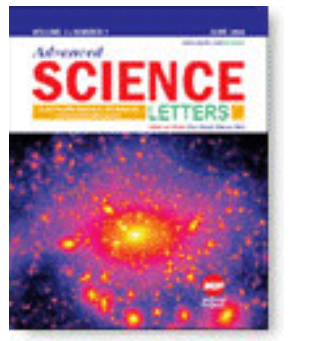

\title{
McCabe's Complexity and CK Metrics on the Internal Quality of Test First Implementation in Malaysian Education Settings
}

Buy Article:

$\$ 105.00+$ tax

(Refund Policy)

ADD TO CART

BUY NOW

Authors: Yahya, Norzariyah"; Bakar, Normi Sham Awang Abu ${ }^{2}$

Source: Advanced Science Letters, Volume 24, Number 2, February 2018, pp. 1201-1205(5)

Publisher: American Scientific Publishers

DOI: https://doi.org/10.1166/asl.2018.10716

\begin{tabular}{|c|c|c|c|c|c|c|}
\hline Abstract & & $\begin{array}{l}\text { 99 } \\
\text { Citations }\end{array}$ & $\begin{array}{l}\text { :日 } \\
\text { Supplementary Data }\end{array}$ & Article Media & $\frac{N}{M e t r i c s}$ & $\begin{array}{l}\boldsymbol{\Psi} \\
\text { Suggestions }\end{array}$ \\
\hline \multicolumn{7}{|c|}{$\begin{array}{l}\text { Test First is promoted in test driven development method as one of an effective Agile manifesto in producing a } \\
\text { better quality applications. Several research have been conducted in education settings and among industrial } \\
\text { practitioners in order to investigate the Test First contribution in producing better quality software compared to } \\
\text { a traditional approach. This paper focuses on studying the internal quality of the project developed by under- } \\
\text { graduates with the implementation of Test First over test last approach in Malaysian education settings. In the } \\
\text { analyses, JHawk is used as the metrics extraction tools, and the analysis utilized the SPSS and G* Power } \\
\text { statistical packages. The metrics collected are based on six object oriented metrics by Chidamber and Kemerer } \\
\text { (CK) and the McCabe's cyclomatic complexity (CC). However, only four CK Metric (Lack of Cohesion in Method, } \\
\text { Coupling between Objects, Weighted Methods per Class, and Response for a Class) were evaluated, in addition, } \\
\text { the complexity is measured based on McCabes's CC. The outcome based on t-test and Mann-Whitney test } \\
\text { shows that none of the metrics is statistically significant for Test First in producing better internal quality; } \\
\text { however, the hypothesis is accepted due to the effect size and achieved power contributed by the Weighted } \\
\text { Method per Class. }\end{array}$} \\
\hline
\end{tabular}

Keywords: CK Metrics; Internal Quality; McCabe's Cyclomatic Complexity; Test First; test last

Document Type: Research Article 
Affiliations: 1: Centre for Foundation Studies, International Islamic University, Malaysia 2: Department of Computer

Science, International Islamic University, Malaysia

Publication date: February 1, 2018

More about this publication? 